$J$ Iribarren $O$.Tecnociencia, virtualidad y poshumanismo: la era infotécnica en tres novelas de Edmundo Paz Soldán

\title{
TECNOCIENCIA, VIRTUALIDAD Y POSHUMANISMO: LA ERA INFOTÉCNICA EN TRES NOVELAS DE EDMUNDO PAZ SOLDÁN ${ }^{1}$
}

\section{TECHNOSCIENCE, VIRTUALITY AND POSTHUMANISM: THE INFOTECHNIC ERA IN THREE NOVELS BY EDMUNDO PAZ SOLDÁN}

\author{
Javiera Valentina Irribarren Ortiz \\ Universidad Católica Silva Henríquez \\ Pontificia Universidad Católica de Chile \\ jirribarreno@ucsh.cl - jvirriba@uc.cl
}

\begin{abstract}
Resumen:
La era infotécnica (Lorca) se caracteriza por consolidar la fusión entre ciencia, tecnología y capitalismo industrial; evidencian la virtualización de los espacios y de las formas de representación; además de la intempestiva entrada del poshumanismo. En las novelas de Edmundo Paz Soldán, dichos fundamentos son actualizados en diversos niveles: la reestructuración incesante de la memoria política que perpetran los cirujanos digitales de la Ciudadela, a partir de la modificación técnica de las imágenes en Sueños digitales; la experiencia hiperreal de la posmetropoli (Soja) en la vida virtual del denominado 'Playground', asi como también en el juego informático y conspiratorio que se da entre criptógrafos y hackers en El delirio de Turing; finalmente, en Iris, la biomecanización de los cuerpos es sustentada dentro de un sistema tecnocrático y colonizador.
\end{abstract}

Palabras clave: Era Infotécnica, Edmundo Paz Soldán, Sueños digitales, El delirio de Turing, Iris

\begin{abstract}
:
The infotechnic era (Lorca) is characterized by its settling the fusion between science, technology and industrial capitalism; showing the virtualization of spaces and representational forms, as well as by the abrupt entrance of posthumanism. In Edmundo Paz Soldan's novels, these fundamental elements are furthered in different levels: the ceaseless restructuration of political memory as perpetrated by the surgical surgeons of the Citadel, through the technical modification of images in Digital Dreams; the hyper real experience of the post-metropolis (Soja) in the virtual life of the "Playground", as well as in the game of digital information and conspiracy that takes place between cryptographers and hackers in Turing's Delirium; finally, in Iris, bio mechanization of the bodies is supported within a technocratic, colonizing system.
\end{abstract}

Keywords: Infotechnic era, Edmundo Paz Soldán, Digital dreams, Turing’s Delirium, Iris

Recibido: 15/6/2017

Aceptado: 25/7/ 2017

\footnotetext{
${ }^{1}$ Esta investigación es resultado de la Tesis para optar al Grado Académico de Magíster en Letras mención Literatura, otorgado el 2016 por el programa de la Facultad de Letras de la Pontificia Universidad Católica de Chile (UC) y el cual fue cursado con Beca CONICYT para Magíster Nacional 2014. Asimismo, esta fue desarrollada en el marco del proyecto Fondecyt Regular n ${ }^{\circ} 1141215$ "Una cartografía de lo audiovisual en la literatura latinoamericana (1915-2015), a cargo del académico UC Wolfgang Bongers Null.
} 
Cuando el ser humano inició su proceso de reproducción en el espacio a través de dispositivos tecnológicos, según McLuhan, afianzó la viabilidad de implementar la metamorfosis entre objeto y sujeto. Independiente del medio, dicho despliegue se transformó en una experiencia única de identificación, dado que el gesto de 'prolongación' gatilló una pulsión narcisista que lo identificó paulatinamente como un 'enamorado de los dispositivos', destinado a experimentar la fascinación de adaptarse a las máquinas que le permitieran proyectar su propio ser en distintas materialidades (68).

En las novelas de ciencia ficción, este imaginario de irrupción maquínica se vio reforzado durante la era neotécnica, iniciada en los albores del siglo XX, puesto que en esta se consolidó la fusión entre ciencia, tecnología y capitalismo industrial. Ahora bien, los componentes específicos que se analizarán son los añadidos en la siguiente época, la infotécnica. En esta se sumó la virtualización de las formas representativas y la conformación del llamado ser-máquina desde una perspectiva poshumanista, que legitimó la ideología tecnocientífica como instrumento de poder en y desde las diversas dimensiones de la cultura, tal como ocurre dentro de las tres novelas distópicas ${ }^{2}$ de Edmundo Paz Soldán escogidas para articular este corpus: Sueños digitales (2001), El delirio de Turing (2003) e Iris (2014).

Según Javier Lorca $(2010)^{3}$, la era infotécnica de la tecnología “subsumió en un mismo conjunto a los animales, los vegetales, los hombres y las nuevas máquinas 'inteligentes': 2 Las novelas analizadas comparten la proyección de un mundo otro y, en cierto sentido, se ajustan a una
propuesta utópica, al modo en que lo plantea Raymond Williams en su artículo "Utopia and Science Fiction"”
(1978). Específicamente, pertenecen al ideario de una utopía comandada por la 'voluntad de transformación' y
por las 'transformaciones tecnológicas', respectivamente. Ahora bien, ambos lineamientos se ajustan al sistema
inverso de las diferentes utopías identificadas por Williams, dado que el ambiente generado se presenta como
adverso y, por lo tanto, se constituye como un escenario donde reina la distopía: el cambio ha generado un
inevitable grado de degeneración social, o bien, el impacto de las nuevas tecnologías está lejos de considerarse
como un avance sociocultural (1).
3 Javier Lorca identifica seis fases de la tecnología y tres movimientos básicos en torno a las máquinas que
aparecen en el género de ciencia ficción. Para efectos de este trabajo, solo se desarrollarán en extenso las dos
última etapas: neotécnica e infotécnica. El resto de las eras se sintetizan así: (1) litotécnica, caracterizada por una
economía de subsistencia, baja productividad, pensamiento mágico, dinámicas de familia y clan; (2)
antropocéntrica, donde se incorporó el metal para crear herramientas funcionales y se instauró el sistema de
esclavitud; (3) eotécnica, donde se ejecutó una sistematización de los recursos naturales como fuente de energía,
se integró la madera y el uso de animales para el trabajo; (4) paleotécnica, que alcanzó su punto álgido en el siglo
XIX, y se sostuvo sobre el mito iluminista del progreso; (5) neotécnica, corresponde al período industrial
comprendido entre 1870 y 1950 , y asociado a la etapa eléctrica de los medios tecnológicos. En relación a los
movimientos operantes de las máquinas, a grandes rasgos, Lorca describe: “en la Cf de primer orden, la máquina
representada por el género es manipulada por el hombre y produce una acción mecánica que tiende a prolongar
el alcance humano sobre el ambiente exterior (movimiento centrífugo). En el segundo orden, instancia de 
todos pasaron a ser concebidos como sistemas de comunicación y control” (53), de manera que el movimiento centrífugo de la relación entre ser-máquina quedó operativizado cuando lo sensoriomotor estrechó una relación simbiótica con respecto a lo cognitivo. En consecuencia, los dispositivos lograron imitar al ser humano en cuerpo y mente, tras convertirse en la denominada máquina antropomorfa -al modo del ya mencionado McLuhan-, que les permitió adquirir el estatus de dispositivos inteligentes.

En este paradigma es donde se ubica la novela Sueños digitales, y cuyo argumento describe un sistema avasallado por la técnica digital, al punto de que su propia historia se ve amenazada producto de la reestructuración incesante de la memoria política que perpetran los denominados "cirujanos digitales" de la Ciudadela: diseñadores expertos en modificación de imágenes, quienes generan un estado extremo de simulación. El protagonista del texto, Sebastián, es uno de ellos y constantemente vaticina la amenaza que constituye el hecho de que los medios tecnológicos sean instrumentalizados con fines políticos dentro de un país, razón por la cual reflexiona de forma contrastiva: "él terminaría admirando a aquellos realizadores capaces de hacer una película sin recurrir a un solo truco digital" (Paz Soldán 54).

Por otra parte, según Pedrós-Gascón, Sueños digitales se constituye como una heterotopía de tipo digital, pues los fundamentos foucaultianos son aplicados en un escenario virtual en el que se desplegaría una suerte de "distopía de desterritorialización informativa" de acuerdo a la conceptualización articulada para este proyecto. En esta heterotopía, la narrativa y la imagen, en un acto de transcodificación de los Nuevos Medios ${ }^{4}$, traspasa el nivel lingüístico y se extiende en el mundo a nivel semiológico, alterando la manera de concebir las dinámicas culturales.

transición, la máquina adquiere autonomía y remeda al complejo orgánico (movimiento orbital), en el tercer orden, la máquina produce información y es interiorizada en el cuerpo (movimiento centrípeto)" (149).

${ }^{4}$ Según Lev Manovich (2001), los denominados Nuevos Medios delimitaron cinco nuevos principios de funcionamiento: (1) Representación numérica discreta, y no continua como en el sistema de engranajes; (2) modulares o fractales, es decir, aquellos que, pese a combinarse y generar nuevos productos, no pierden su independencia; (3) automatización, dado que la posibilidad de existencia de un referente es aún más remota que la eventual presencia del elemento genuino; (4) variabilidad, al poseer infinitud de versiones y, por lo tanto, posicionarse desde la interactividad que implica la lógica hipermedial; (5) transcodificación, ya que su modo de procesamiento impacta directamente en el carácter representativo de las dinámicas culturales en las que este se inserta. 
De manera similar, dicha transcodificación es visible en la novela Iris, a través de la articulación de un mundo futuro plagado de imágenes narrativas, que recrean una sociedad avasallada por la tecnocracia. Un espacio también heterotópico donde la preeminencia de la imagen es patente en la construcción de representaciones, puesto que la descripción narrativa logra que las concreciones objetivas de ese mundo posible retomen la potencia virtual de los signos iconológicos, como medio productivo de expansión ficcional.

En Sueños digitales la problematización en torno a la persistencia de la memoria queda plasmada en las interrogantes que continuamente se plantea su protagonista: “¿Y qué era hoy tener una memoria fotográfica?” (Sueños, Paz Soldán 136). El autodenominado retratista digital se percata de que, en un mundo tecnocultural, la memoria se posiciona como una entidad peligrosamente maleable; y más aún, la memoria fotográfica se concibe como una habilidad que solo se erige en la medida que reproduce instantes desterritorializados.

El bisturí digital es el medio que faculta la técnica de creación y recreación de los denominados seres digitales, de las quimeras digitales. 'Todo empezó con el cuerpo de Raquel Welch y la cabeza del Ché' es la consigna que patenta el triunfo de la técnica frente al tiempo, pues la mutabilidad se nos presenta como atributo inherente a la materialidad de los cuerpos virtuales. Ahora bien, la paradoja está en que la realidad se difumina fuera del referente, dado que el cambio opera directamente en su reproducción:

MTV: una imagen de Michael Jackson con la tez tan blanca que parecía albino. Pobre Michael, se había sometido tantas veces a cirugías estéticas y cambios de pigmentación en la piel, sin sospechar siquiera que algún día, en un futuro no tan futuro -un futuro que ya había llegado y que había vencido al presente sin que éste se diera cuenta-, los algoritmos lograrían mucho mejor y con más facilidad que los bisturís el cambio que buscaba con tanto afán (50-51).

De acuerdo a este escenario, además, la sofisticación de la tecnología digital permite incluso que el cuerpo modificado adquiera una mayor verosimilitud que la propia realidad, de manera tal que las copias también se someten al juego de una era tecnológica que se posiciona como “deseante”, si seguimos la lógica del Cuerpo Sin Órganos ( $\mathrm{CsO})$ de Deleuze y Guattari. En este sentido, el estado de simulación se constituye como una red que no es estrictamente material, pero tampoco inmaterial; es más bien un flujo continuo que afecta a todos los planos 
y formas de representación, por lo que cualquier tipo de cambio generado en esta, necesariamente modifica el imaginario en su conjunto, lo desterritorializa.

A diferencia del otrora collage o del patchwork -con tijeras y pegamento-, ahora la mutación se actualiza en y a través de símbolos virtuales. Sebastián rearticula el paisaje y a sus seres a partir de colores únicamente pensados desde una paleta computarizada y de íconos que traducen funciones algorítmicas. Igualmente, las modificaciones a los colores y al espacio no son casuales; la operación narrativa es similar a las descripciones del mundo distópico de Iris, cuyos espacios están avasallados por los artificiosos colores que generan las nubes tóxicas.

Bajo este escenario, entonces, la fotogenia como huella insigne o atributo específico inmaterial de la imagen es inoperante, puesto que ahora dicha cualidad no procedería de la imagen misma, sino de la experticia técnica de quien aplique el algoritmo. Es por ello que en el mundo de Sueños digitales se hablará de una posfotogenia, siguiendo la lógica que Edward Soja (2008) identifica en lo 'post', a la hora de definir las llamadas posmetrópolis. En ellas, el gesto deconstructivo es de tal envergadura que logra modificar incluso la manera en que nos desenvolvemos en el espacio social, dado que este se transmuta a un plano eminentemente hiperreal, y cuya especificidad es dada en un reducto erigido en el seno de la simulación. Por consiguiente, el exceso, los colores hiperkinéticos -señala el personaje principal en algún momento-, las intensidades, las avasallantes luminosidades, constituyen lo necesario para que la nueva imagen opaque a la original. Se genera así una representación que, de acuerdo a su carácter expansivo, su afán de multiplicación y de metamorfosis, absorbe el escenario inicial y se superpone desde el mundo hiperreal.

Por otro lado, es relevante cómo la manipulación de la imagen deja de lado los estatutos de la Revolución Industrial, pues esta se da en el marco de un nuevo paradigma: la Revolución Digital. Una que no precisa de un cuarto oscuro para revelar la fotografía, sino de uno iluminado por los destellos de las pantallas o de las interfaces modales, tal y como se visibiliza en la novela cuando se describen las oficinas del periódico "Tiempos Posmodernos". Asimismo, la revolución digital no configura sus imágenes en el presente al modo de un fotógrafo, por el contrario, asume la necesidad de someterlas a un proceso de posproducción a cargo de los 'Picassos digitales'. 
En este punto, cabe destacar la relevancia implicada en el nombre del medio informativo que alberga a los Seres digitales, “Tiempos Posmodernos”, puesto que en él se evidencia, además, que la revolución fordiana ha sido superada. En dicha época, el objetivo era crear un sistema de engranajes que se manifestara como extensiones del propio cuerpo humano; pero en la digital, se da a partir de la profusión del sistema nervioso humano en la red neuronal del espacio virtual -tal como se ha mencionado en consideraciones previas-, y cuyo cambio se ha identificado como el paso desde la era neotécnica a la era infotécnica.

Igualmente, dada la irrupción de los Nuevos Medios en ambas eras, tales como la fotografía, el cine, la televisión, internet, entre otros; es posible construir y transmitir un nuevo tipo de experiencia que retrotrae de forma completa el universo representado: es la facultad de proyectar una experiencia háptica de lo sensible, en la que las formas se objetivizan a través de un dispositivo que permite la transmisión. Es la capacidad de crear una hiperrealidad que va más allá de la representación caleidoscópica de un elemento o sistema cultural, puesto que ahora el mundo es configurado a partir de estructuras específicas de intercambio, fundadas en modos situados de experimentación de lo sensible y, en suma, de su propia construcción estética (Rancière 22). Es la viabilidad de concebir la historia y el arte a partir de un régimen estético de lo sensible, cuyo carácter particular recae principalmente en desdibujar los límites tradicionales de conformación discursiva y redibujarlos desde una práctica teórico-crítica de la experiencia.

Es así como el carácter modular y variable de los mencionados Nuevos Medios, contribuye en la manifestación sintomática del denominado CsO. En otras palabras, ocurre que las imágenes producidas por los dispositivos son potencialmente desterritorializables, por tanto se articulan en un devenir perenne y modular: los seres digitales son mutilados y recreados incesantemente, al punto de que logran apropiarse y reapropiarse ad infinitum de estatutos icónicos de la propia cultura. Dicho modelo, por lo demás, es el que se replica al momento de iniciar el borramiento de las escenas pasadas del exdictador, ahora gobernante, Montenegro 5 . La Ciudadela espera que Sebastián logre una avanzada similar a la de un tejido canceroso avasallante, mediante la aplicación de la técnica digital a las fotografías que delatan

\footnotetext{
${ }^{5}$ En referencia al militar boliviano Hugo Banzer, dictador entre los años 1971 y 1978; y gobernante electo por vía democrática durante el período de 1997 y 2001.
} 
las prácticas de horror de dicho gobernante. Así, el personaje principal cambia y reorienta la historia pasada, de tal modo que la existencia de la copia modificada siembra dudas genuinas en la memoria de los sujetos; dudas que buscan la obsolescencia completa del pasado, mediante una transmutación progresiva y agresiva.

En cierta forma, y específicamente, se podría establecer que la operación Montenegro se perfila como una meseta del $\mathrm{CsO}$, dado que al ser esta última una región de intensidad continua y sin interrupción (Bateson en Deleuze y Guattari 158), por lo tanto, el flujo incesante, que pasa a través de ella, ineludiblemente faculta desterritorializaciones. En el caso de Sueños digitales, esto se explica además debido a que la intención de la Ciudadela no se agota en el borramiento o reestructuración de las 'imágenes' de Montenegro, sino que también se extrapola a los sonidos, discursos e imágenes en movimiento. Señala Sebastián: "le habían hecho creer que él era una pieza fundamental del proyecto cuando en realidad era tan sólo una pieza más" (Paz Soldán 160); era una estación más de las distintas piezas que actuaban, sin avizorarlo, de forma interdependiente. Los seres, palabras y sonidos digitales, pese a ser mutilados y generar infinitos resultados distintos a su referente, logran proyectar el flujo de un CsO que despliega sin límite exterior.

La imagen, y aún más la quimera digital, es solo un nodo más de un proceso de desterritorialización que jamás culmina. Toda máquina deseante es articulada para alcanzar un $\mathrm{CsO}$ nunca satisfecho y siempre en expansión. Un proceso de cambio inagotable que puede amenazar incluso a su propio gestor, dado que la reconfiguración de la historia se aplica a todas las estructuras cognitivas de percepción. En este sentido, se enuncia en el libro de Paz Soldán:

Imaginó [Sebastián] a la Ciudadela como uno de esos organismos autónomos que había visto en alguna película de ciencia ficción o en algún videogame en el departamento de Pixel. Un organismo que se autogeneraba, que creaba a quienes lo creaban y luego se deshacía de ellos. Los caminos se cerraban, pronto no habría puentes para cruzar, pronto vendrían en su búsqueda (Sueños, 218).

En consecuencia, se actualiza la amenaza del filme Dark City (1998) de Alexander Proyas, en cuanto el territorio y las operaciones sociales son objeto de constante flujo, por 
causa de los experimentos que seres indolentes y 'a-emocionales' (de apariencia vampiresca, similares al mítico Nosferatu) aplican continuamente a los humanos, con el objetivo de develar aquello que los hace sentir.

Ahora bien, y como aparato de Estado, en su intento por territorializar, la operación de la Ciudadela culmina en desterritorializaciones progresivas, dado que el objetivo de sus instrumentos de control de repercutir indirectamente en las operaciones particulares de los individuos, genera un efecto dominó imparable que afecta la memoria en todas sus dimensiones. No obstante, el atributo expansivo del borramiento funda una paranoia legítima, visible en el personaje de Sebastián: el incesante flujo que los técnicos digitales lograrían, en primer lugar, ¿imposibilita la idea de considerar la operación Montenegro como un organismo finito? La Ciudadela, como organismo autónomo, pretende desplegar un plan político de recambio, uno encargado de instrumentalizar los Nuevos Medios en favor del blanqueamiento de la historia, no obstante, también prefigura y alienta un universo en constante cambio.

En segundo lugar, y bajo esta lógica, tratar de trazar una puerta exterior a un potencial $\mathrm{CsO}$ se perfilaría como un proyecto imposible. La idea de modelar controladamente la memoria a través de desterritorializaciones es un arma de doble filo: práctica y efectiva al propósito; pero también es una acción que se escinde y se revela frente a su gestor. Al intentar fijar parámetros a una entidad automatizada por los Nuevos Medios, ineludiblemente también se afecta a los precursores y técnicos del proyecto. En Sueños digitales el borramiento se extiende a la vida de los Picassos digitales y, eventualmente, a toda huella (o persona) que manifiesta el más mínimo rastro de duda o de consciencia de verse inmerso en una hiperrealidad. Por lo tanto, se gesta un eterno retorno que se entrampa en el afán de aniquilamiento recíproco, al existir la necesidad de eliminar incluso a los encargados de tal tarea.

Igualmente, la configuración de una hiperrealidad es introyectada en el imaginario urbano y se actualiza desde la pulsión hipermedial: "Pixel lo miró (a Braudel) con expresión de desamparo, como si no entendiera esa compulsión que lo llevaba a navegar la red sin tregua - pez hambriento en aguas eléctricas-, a apasionarse de un tema extravagante que había encontrado por casualidad, y dejarlo dos días después sin un pestañeo de remordimiento)” (Sueños, Paz Soldán 77). La variabilidad de los Nuevos Medios se hace patente y la lógica del 
hipertexto logra que los referentes sean reemplazados por sus íconos, tal como se describía en páginas previas respecto a la operación realizada por los bisturíes digitales.

No obstante, y en este ámbito, se deja de manifiesto que la materialidad no constituye evidencia, pues el artista-técnico relega a los referentes -y al nitrato de plata- a un estado criogénico. Sin embargo, y paradójicamente, también se enfatiza en que toda lógica de reproducción implica una modificación, pues la manipulación -la desterritorialización incesante- es en sí misma un síntoma pretérito: toda foto se articula y se "digitaliza técnicamente"; los Nuevos Medios lo facultan y lo dejan al alcance de la mano, pero el afán de simulación y de reconfigurar la memoria individual y colectiva es tan antigua como el mito de Narciso. En la era de la industrialización y en la era de la digitalización, toda imagen reconfigura realidades a través de imágenes posfotogénicas: si hoy Sebastián prefería conocer al técnico que producía los trucos en los albores de la era industrial del cine, antes se anhelaba conocer al actor que los pseudoprotagonizaba.

Es así como avizoramos que el carácter de simulación alcanza su punto álgido, pues se infiltra tanto en las estructuras de pensamiento individuales como en las operaciones sociales. La Cochabamba de Sueños digitales se transforma en el seno de la Simcity: "un lugar donde las simulaciones de un supuesto mundo real atrae y activa incesantemente nuestra imaginación urbana y se infiltra en la vida cotidiana" (Soja 8). De esta manera, el gesto deconstruccionista del panóptico electrónico en la era de la simulación se afianza, dado que se vive en el centro de una peligrosa hiperrealidad digital: Pixel intuye que alguna vez existirán videojuegos que se conviertan en la vida misma; el mismo personaje describe el juego "Immersive Imaging", en el cual los usuarios de la red pueden navegar interactivamente en distintos escenarios virtuales; Sebastián prefigura la imagen de un prostituto digital en torno al avatar que Pixel construye para dicho juego; además, Sebastián espera que algún día tengamos la posibilidad técnica de escoger los pedazos de realidad que deseamos ver en nuestras ventanas.

En este punto es pertinente mencionar la Simcity del "Playground", mundo virtual que se describe en El delirio de Turing. En dicho espacio, los íconos digitales unidimensionales proyectan un punto de vista crítico con respecto a las dinámicas experimentadas en un escenario comandado por una doble proyección virtual, pues el avatar del sistema representa a 
un sujeto que se enuncia como referente otro de su propia conformación real, tal como se da en el caso de Kandinsky: Báez se metamorfosea en un hacker que, a su vez, es representado por medio de un avatar homónimo al interior del Playground.

Del mismo modo, el juego informático y conspiratorio que se genera con respecto a la relación dada entre los criptógrafos de la Ciudadela y los hackers del Playground, encarna en sí misma la extremación de esa incesante simulación: la batalla solo es efectiva en un mundo virtual otro, anónimo y modular; uno que además se sustenta sobre la base de evitar que las contrapartes revelen al mundo real los misterios ocultos de una Simcity fundada en la proyección.

Por otro lado, dicho espacio virtual se conforma como una figura heterotópica ${ }^{6}$ dentro de la novela, al igual que el cibercafé "Portal de la Realidad" al que acudían los hackers -y que se situaba cerca del Puente de los Suicidas, otro espacio de similares características. En este mismo sentido, el efecto de este reducto heterotópico, de la subcultura del Playground, se propaga incluso en relación a un ideario político. Es el caso de los ciberactivistas de la Resistencia y, particularmente, de quienes conforman la Recuperación, y cuyo objetivo por lo demás se materializa en la causa extrema de crear un "Ciberestado" fuera de los límites de la materialidad.

En consecuencia, el régimen de lo háptico se potencia frente a la posibilidad de proyectar el mundo más allá de una imagen estática e intemporal; es la facultad de lograr un

\footnotetext{
6 Michel Foucault en las conferencias "Utopías y heterotopías" y "El cuerpo utópico" define el término de heterotopía. En ellas realiza un recorrido por las distintas migraciones que el concepto de espacio ha experimentado a lo largo de la historia. Primero fue considerado como una "locación", pues el espacio en la Edad Media era jerarquizado o polarizado; luego pasó a ser una "extensión", a partir del cambio en autoperceptivo del espacio, originado por la teoría heliocéntrica; y, finalmente, se definió como una "ubicación", vale decir, una vecindad entre distintos puntos, que no necesariamente comparten. Lo anterior, es fruto de la redefinición del espacio que presupuso la irrupción de lo tecnológico y el cambio abismante en la demografía mundial. Señala Foucault que "vivimos en una especie de vacío" (1), pero no dentro de él sino en uno donde las relaciones no son superponibles. Es así como plantea a la utopía -lugar sin espacio real- como contraria a las heterotopías - espacios reales, que a la vez son contraespacios. Para serlo, deben cumplir con seis características fundamentales: 1. puede ser un espacio de crisis (mundo antiguo) o de desviación (mundo nuevo), éste último es el que le interesa; 2. asume una función distinta a la normativamente designada; 3 . posee la propiedad de la yuxtaposición, caracterizada no por la idea de compartir el espacio, sino por situarse en el mismo punto, independiente del cometido. Pone como ejemplo el cine, la proyección de un espacio otro en un espacio determinado, que se conjuga con la noción del espacio propio, que es a su vez un espacio otro para cada cual que ve la pantalla; 4. es heterocrónico, pues rompe con el tiempo tradicional; 5 es de apertura y cierre, ya que solo penetra realmente el que es admitido o el iniciado. No se trata solo de posicionarse, sino de ser y sentirse parte de él; 6. puede ser un espacio ilusorio que por sus vicios funciona como denuncia del real, o bien, uno perfecto y distinto, que puntualiza a modo comparativo lo anárquico y caótico del real.
} 
hiperrealismo representativo que ya no prefigura a la imagen como el punto de partida, sino como un asidero de innumerables y mutables proyecciones futuras. Es así como, además, se logra problematizar la implicancia de lo virtual en la figura de las tecnologías digitales, en tanto materializa el deseo prístino del narciso: vivir a través de los ojos de una representación virtual que emule las mismas dinámicas culturales que experimentaría en el espacio sensible, pero en un mundo otro: "ha dormido profundamente un par de horas, y ha tenido un sueño extraño en el que se encarnaba en un Ser Digital, ingresaba al Playground y pedía asilo en una embajada: no quería regresar a Río fugitivo. Se lo concedía y sentía una inmensa liberación” (Delirio, Paz Soldán 301). En la misma lógica, por lo tanto, la perspectiva crítica manifiesta un gesto de remediación -al modo de Bolter y Grusin ${ }^{7}$ - en tanto los referentes logran ser partícipe de la propia experiencia de mediación, pues su transmutación extrema es la que precisamente genera la vida cibernética.

Así como en Sueños digitales la máquina (encarnada en la implementación técnica de los dispositivos) se cuela por entre las formas de representación, en El delirio de Turing esta no solo se infiltra en el espacio virtual, sino también en el escenario real: se advierte en la imagen de una mujer con un brazo metálico que atiende en el café Portal a la Realidad; también en la idea de la hormiga eléctrica conectada a la tierra, la cual redunda en los pensamientos del personaje de Turing; finalmente, este último personaje se conforma como un sujeto con pensamiento telegráfico, que además se siente un dispositivo poshumano plagado de tubos que lo conectan a la realidad.

En el mismo ámbito, cabe destacar que en esta novela la problematización en torno al medio -y los eventuales actos de remediación- es constante, pues se articula como fundamento para establecer la imposibilidad de la persistencia frente a la finitud física del ser humano. A partir de la figura de Albert se desarrolla una reflexión respecto a los elementos que nos diferenciaría de los dispositivos y que nos permitirían dilucidar la clave que, aparentemente, le ha permitido a este personaje lograr la transmutación cognitiva y corpórea:

\footnotetext{
${ }^{7}$ Con ello también se refuerza la idea que Paz Soldán identifica en el texto "Vanguardia e imaginario cinemático: Vicente Huidobro y la novela-film", en el sentido de que recupera el gesto de remediación material-estético articulado por Huidobro, y que se orienta a problematizar las formas hápticas de representación en relación a Cagliostro: novela-film (1934). Asimismo, dicho acto es recuperado por el boliviano al momento de integrar figuras de virtualidad en sus novelas. Del mismo modo, la remediación subjetiva postulada con respecto al ambiente distópico que generaría un escenario avasallado por el dominio tecnológico en La próxima (1934), es coherente con diversos argumentos que Paz Soldán proyecta en sus novelas.
} 
Cada uno de nosotros es, a su manera, una máquina universal de Turing. El mundo funciona como una máquina universal de Turing. Hay un algoritmo que regula todos los latidos del universo... O quizás se trata de algunas líneas de código... Todos los pasos. Desde los más sencillos a los más complejos... Esto se comprobará. Una vez que haya la tecnología adecuada... Podrían pasar años. Décadas. Siglos. Lo único cierto es que yo... que me desangro en una prolija habitación de hospital. Estaré presente (313).

De este modo, y en analogía a la máquina universal de Turing, se plantea la posibilidad de encontrar en el ser humano una huella que le permita descubrir el sistema operativo que lo moviliza, al modo en que un ordenador posee secuencias específicas que ponen en marcha su funcionamiento. Por otra parte, en la novela se da especial énfasis en que el hacker sería el encargado de descubrir dichos misterios, puesto que ya estaría familiarizado con los códigos fundamentales que permitiría establecer una asociación entre las operaciones del ser y de la máquina. Es él quien se encarga de establecer proyecciones entre la conformación de los seres humanos y las máquinas estéticas de sexto orden ${ }^{8}$, cuyo cometido se enfoca precisamente en canalizar energías que activen la generación de acciones autónomas que faculten la autosustentación de dicho dispositivo, tal como lo distingue Gene Youngblood (2013) cuando lo caracteriza como un sublime "instrumento parasicológico para la proyección directa de pensamiento y emociones" (212).

En este punto, emerge la implicancia de la teoría poshumana en la configuración de dichos seres híbridos. Al respecto, Katherine Hayles señala:

\footnotetext{
${ }^{8}$ Youngblood señala que, en el escenario de la 'tecnoesfera', es posible evidenciar la transición desde la creación de máquinas funcionales hasta la reconfiguración estética de las mismas, de modo que se materialice la aplicabilidad estética de las computadoras digitales en la producción de diversos objetos culturales: "está bastante claro en qué dirección sigue la relación simbiótica del hombre con la computadora: si la primera computadora fue el ábaco, la última computadora será el sublime dispositivo estético: un instrumento parapsicológico para la proyección directa de pensamientos y emociones" (212). Asimismo, el autor identifica la primera etapa de la computadora como un acto de fusión sinérgica entre hombre-máquina; en la segunda, la computadora es indispensable en la producción artística y puede tomar decisiones en base a lineamientos programados. La tercera etapa se caracteriza por otorgar a la computadora la capacidad de tomar decisiones autónomas en torno a posibilidades alternativas de creación, aunque sin parámetros programados; en la cuarta etapa dichas decisiones anticipan incluso a las del artista; mientras que, en la quinta, se prescindirá del artista como tal, pues la máquina estética será capaz de proyectar las invenciones del propio creador.
} 
the posthuman view configures human being so that it can be seamlessly articulated with intelligent machines. In the posthuman, there are no essential differences or absolute demarcations between bodily existence and computer simulation, cybernetic mechanism and biological organism, robot teleology and human goals (Hackers, cit. en Brown 117).

En este sentido, la factibilidad de fusionar la biología con un sistema de carácter digital queda de manifiesto al momento de proyectar la biomecanización de los cuerpos vivos. Ahora bien, este acto es mayormente ostensible en la novela Iris, puesto que dicho universo ficcional se conforma a partir de una numerosa cantidad de seres-máquinas, tales como: krazikats y wakidogs (gatos genéticamente modificados que dan toda la atención a sus dueños), chitas (felinos metálicos de combate), artificiales (desterrados, exconvictos o accidentados en estado crítico de Munro, a quienes se le inserta una nueva memoria y/o se le reemplazan partes de su cuerpo para ejercer labores de seguridad en el Perímetro), entre otros. Asimismo, en esta configuración es relevante cómo las imágenes narrativas estructuran un espacio donde dichos personajes se encuentran mediados por cuantiosas máquinas y operaciones afines: electrolapiz, excavabots, lenslets, suits, liftface, etc.

De manera similar, la proyección de seres poshumanos puede advertirse en las descripciones que se hacen, por ejemplo, del personaje de Xavier: poseía suits (drogas) en una caja que se desprendía desde su cuello; ocupaba lentlets en sus ojos y estos le permitían traducir el idioma irisino, ver datos de interés y, en definitiva, aumentar su experiencia de realidad. También lo encontramos en la figura de los shanz Chendo Chendo, Carreño y Reynolds, quienes además son denominados artificiales por poseer la llamada "memoria reciclada" que los convierte en san-zombis:

queríamos inventarle un pasado a Reynolds mas era imposible. Los artificiales no tenían infancia ni adolescencia. Eran construidos así, nacían adultos. Les injertaban una memoria que les daba una historia, más habían tan bien como nos q'esa memoria era artificial. La podía cambiar si alguna experiencia no les gustaba, algún trauma con el que no se identificaban. Decían que había un mercado negro pa las memorias de los artificiales (135). 
Por otra parte, en Iris no solo se devela un gesto crítico frente al funcionamiento de un sistema sustentado por una tecnocracia colonizadora y por el abuso de la biomecanización de los cuerpos, sino que también se reflexiona en torno a los excesos del capitalismo moderno mediante la descripción de ciudades derruidas, deterioradas por eventos nucleares y sumidas de forma permanente bajo grandes nubes tóxicas.

Además de dichos gestos críticos, en la novela se insiste en la posibilidad de hacer frente a los vicios de la era infotécnica a partir de una experiencia que se diferencie de la hiperrealidad proporcionada por los insumos tecnólogicos. Frente a ello, en Iris se propone el uso de drogas sintéticas que, en el imaginario "neotribal" de los irisinos -seres blanquecinos o de piel anaranjada, con pinturas fluorescentes y anillos al cuello-, se liga al alcance de la trascendencia y la superación del sometimiento ante un régimen tecnocientífico que los ata al estado dictatorial de Munro. En este aspecto, la propuesta poshumana queda desmitificada, ya que la persistencia de la consciencia solo lograría a partir de una conexión mística y no mediante la conquista de los principios que permitirían derrocar la finitud del cuerpo tras conquistar la simbiosis cibernética del ser-máquina.

Los dispositivos tecnológicos se nos presentan como un instrumento de poder que potencia las dinámicas dictatoriales en universos distópicos: caso que se ve extremado la novela Iris, pero que no deja de estar presente -en clave realista- en Sueños digitales y en El delirio de Turing. Además, y en dos estas últimas, la operativización de la técnica digital al servicio de la ideología genera un instrumento de borramiento de la memoria política de un país y, por lo tanto, la aplicación de un sistema de control implícito que se apodera transversalmente de la información ofrecida a través de las plataformas tecnológicas. Al mismo tiempo, se caracteriza el alcance del acto de remediación en los mundos virtuales descritos en las dos últimas ficciones: la vida virtual del "Playground" en el Delirio de Turing y el juego "Immersive Imaging” de Sueños digitales. Finalmente, la articulación de un sermáquina en la era infotécnica es caracterizada por la conformación de entidades maquínicas poshumanas, en el caso de los llamados “artificiales” de Iris: seres híbridos que esperan lograr la afamada trascendencia temporoespacial. Asimismo, la pulsión narcisista y el servomecanismo al que se somete el individuo frente a los medios tecnológicos, en dicha 
novela se nos presenta como una amenaza latente, al representar una sociedad que operativiza la tecnociencia al servicio de una ideología política dictatorial.

En suma, la proliferación e introyección de los medios y de la tecnología en la base material de sus referentes sociales es ostensible a través de estas novelas. No solo a nivel temático, sino también en una dimensión estética; las diferentes manifestaciones de la máquina contribuyen a establecer contrapuntos críticos con respecto a las posibilidades de representarse expansivamente en el mundo y en la ficción. Por último, es interesante que las aproximaciones posean un carácter distópico, pues mediante dicha formulación se pone por sobreaviso la necesidad de estatutos éticos, que medien posibles escenarios culturales pertenecientes a la era infotécnica y que se encuentran invariablemente dominados por la tecnociencia.

\section{Bibliografía}

Bolter, J. y Grusin, R. Remediation. Understanding New Media. Cambridge: MIT Press, 1999. Impreso.

Brown, Andrew. "Hacking The Past: Edmundo Paz Soldán's El delirio de Turing and Carlos Gamerro's Las islas". Arizona Journal of Hispanic Cultural Studies. (2006): 115-129. Web. 13 may. 2016. https://muse.jhu.edu/article/21455

Dark City. Dir. Alex Proyas. New Line Cinema y Mystery Clock Cinema, 2008. Fílmico.

Deleuze, G. y Guattari, F. Mil mesetas: capitalismo y esquizofrenia. Trad. José Vásquez Pérez. Valencia: Pre-Textos, 1988. Impreso.

Foucault, Michel. "Topologías". Revista Fractal. (2008): 1-20. Web. 13 may. 2016. http://www.mxfractal.org/RevistaFractal48MichelFoucault.html.

Huidobro, Vicente. La próxima. Santiago: Ediciones Walton, 1934. Impreso.

------. Cagliostro: novela-film. Santiago: Andrés Bello 1978. Impreso.

Lorca, Javier. Historia de la ciencia ficción y sus relaciones con las máquinas (de las naves espaciales a los cyborgs). Buenos Aires: Capital Intelectual, 2010. Impreso.

Manovich, Lev. El lenguaje de los nuevos medios de comunicación: la imagen en la era digital. Trad. Óscar Fontrodona. Buenos Aires: Paidós, 2006. Impreso.

McLuhan, Marshall. Comprender los medios de comunicación: las extensiones del ser humano Trad. Patrick Ducher. Barcelona: Paidós, 1996. Impreso.

Paz Soldán, Edmundo. El delirio de Turing. Madrid: Alfaguara, 2003. Impreso.

------.. Iris. Madrid: Alfaguara, 2014. Impreso.

------. Sueños digitales. La Paz: Alfaguara, 2000. Impreso.

--------. "Vanguardia e imaginario cinemático: Vicente Huidobro y la novela-film”. Revista Iberoamericana. Ene.-Marz. (2002): 153-163. Impreso.

Pedrós-Gascón, Antonio. "Heterotopías libres: simulacro y realidades en La sombra cazadora (Suso De Toro) y Sueños digitales (Edmundo Paz soldán)”. Tropelías. Revista de Teoría 
de la Literatura y Literatura comparada. Web. 13 may. 2016. https://www.academia.edu/862795/_Heterotop\%C3\%ADas_digitales_simulacro_y_reali dades_en_La_sombra_Cazadora_Suso_de_Toro_y_Sue\%C3\%B1os_Digitales_Edmund o_Paz_Sold\%C3\%A1n_

Rancière, Jacques. "La división de lo sensible. Estética y política". Trad. Antonio Fernández Lera. Academia. $\quad$ Web. $13 \quad$ may. 2016. https://www.academia.edu/1859514/Ranci\%C3\%A8re.La.divisi\%C3\%B3n_de_lo_sensi ble

Soja, Edward. Postmetrópolis. Estudios críticos sobre las ciudades y las regiones. Madrid: Traficantes de sueños, 2008. Impreso.

Youngblood, Gene. Cine expandido. Trad. María Ester Torrado. Argentina: Editorial de la Universidad Nacional Tres de Febrero (EDUNTREF), 2012. Impreso.

Williams, Raymond. "Utopia and Science Fiction". Science Fiction Studies. Nov. (1978): 111. Web. 13 may. 2016. http://www.depauw.edu/sfs/backissues/16/williams16art. htm 